\title{
CARNASACRA - SÍMBOLO DE RESISTÊNCIA NEGRA E OBJETO DE MANIFESTAÇÃO POPULAR
}

\author{
Juliana Hoffmann Rodrigues
}

\begin{abstract}
Graduada em turismo pela Universidade Paulista (2005), com Especialização em Gestão de Eventos Culturais. Pesquisa realizada sob orientação do Prof. Dr. Juarez Tadeu de Paula Xavier (Unicid)
\end{abstract}

\section{Resumo}

Este artigo examina o desenvolvimento de uma comunidade que evidencia sua luta e resistência para a construção de suas referências. Um povo que luta ainda hoje pela preservação de sua história, de sua cultura e da formação de sua identidade, através de manifestações, em especial o carnaval. Este texto pretende compreender a contextualização histórico-cultural da cidade de Sacramento, os acontecimentos que deram origem ao carnaval e a descrição deste, assim como resgatar o ideal de origem desta manifestação de resistência com função de combate ao racismo e à exclusão social e construção do seu referencial simbólico.

Palavras chave: Manifestação popular; resistência negra; cidadania; identidade cultural; carnaval.

\section{Abstract}

This article examines the development of a community showing their struggle and resistance for the construction of their references. People who still fight for the preservation of its history and its culture and formation of their identity, through demonstrations, especially the carnival. This essay attempts to understand the historical and cultural background of the city of Sacramento, the events that gave rise to the carnival and this description, as well as rescue the ideal source of this outbreak, the resistance function to combat racism and social exclusion and build their the symbolic.

Keywords: Demonstration popular; black resistance; citizenship; cultural identity; carnival.

\section{Resumen}

Este artículo examina el desarrollo de una comunidad mostrando su lucha y resistencia para la construcción de sus referencias. Un pueblo que aún lucha por la preservación de su historia, su cultura y la formación de su identidad, por medio de manifestaciones, especialmente el carnaval. Este trabajo trata de entender el trasfondo histórico y cultural de la ciudad de Sacramento, los fatos que dieron origen al carnaval y la descripción de esta, así como el rescate de la fuente ideal de esta manifestación de la función de la resistencia a la lucha contra el racismo y la exclusión social y construcción de su referencial simbólico.

Palabras clave: manifestación popular; la resistencia negra; la ciudadanía; la identidad cultural; el carnaval. 


\section{CARNASACRA - SÍMBOLO DE RESISTÊNCIA NEGRA E OBJETO DE MANIFESTAÇÃO POPULAR}

\section{Introdução}

A escolha do tema deu-se através da ideia de uma profissional de turismo residente da cidade de Sacramento em Minas Gerais, que buscava um tema a ser estudado e que fossem elaboradas propostas para melhorias na cidade. Veio então a procura pelas manifestações culturais evidentes neste município e então a escolha do carnaval por se tratar de uma manifestação que atrai grande quantidade de turistas para a cidade e move a comunidade negra na busca por seus valores e pertencimento à sociedade.

Para examinar tal realidade, foi empreendida uma pesquisa de cunho qualitativo. O estudo compreende o período de 1926 à 2009 através de pesquisa documental e da observação participante, que permitiram a coleta de dados pertinentes ao assunto, buscando-se a interação das memórias do carnaval entre pesquisa histórica e depoimentos.

Através da coleta de dados foi possível perceber como após anos de Abolição e de gerações que lutavam por uma manifestação social, observa-se ainda a necessidade da continuidade deste ideal de liberdade e da busca constante por suas referências. Evidencia-se assim, a capacidade dos negros da recriação de seu próprio universo simbólico.

A partir desta hipótese, fez-se uma análise do carnaval de Sacramento, em especial da Escola de Samba 13 de Maio (1959), que desde sua origem tem mantido características fundamentais de resistência.

Para tanto, foi utilizada a abordagem de carnavalização através da teoria de Mikhail Bakhtin, o multiculturalismo de Stuart Hall, a manifestação tratada por Carlo Ginzburg e a história social do negro tratada por Clóvis Moura.

Apontando um conceito amplo de multiculturalismo através das observações de Hall: "Não importa quão diferentes seus membros possam ser em termos de classe, gênero ou raça, uma cultura nacional busca unificá-los numa identidade cultural, para representá-los todos como pertencendo à mesma e grande família nacional”. (2004, p.59)

Para Hall, o Multiculturalismo seria o encontro de diversos elementos culturais em um mesmo espaço físico e que alteram as características de uma sociedade.

Em uma sociedade multicultural, procuram-se estratégias para o controle das diferenças culturais e raciais através da integração social e reconhecimento dos diferentes, mas isso não implica em respeito a esse grupo diferente e nem respeito a sua 
cultura.

Contextualiza-se o município de Sacramento destacando estes elementos culturais e resgatando esta efervescência na atualidade.

\section{Contextualização histórica da cidade de Sacramento}

Sacramento é um município do Estado de Minas Gerais com uma população de 22 mil habitantes (dados de 2005).

A origem da cidade de Sacramento é confundida com a de Desemboque, núcleo inicial de Sacramento e berço de toda civilização do Triângulo Mineiro e que hoje tem grande valor histórico-cultural. Mas teve a mesma origem que Santa Maria e foi fundada em 24 de agosto de 1820 pelo cônego Hermógenes Casimiro de Araújo Brunswick.

É importante citar a sesmaria de Santa Maria, pois por volta de 1827 criou-se ali uma fazenda rural composta por escravos. O filho de uma escrava, desaparecido no dia de seu nascimento, foi criado em uma fazenda em São Roque de Minas, próximo ao município de Sacramento, pertencente à família Gonçalves e de quem herdou o nome de família. Alguns anos depois, ele retorna à região, casa-se com Ana Petrolina de Araújo e juntos criam em Santa Maria uma comunidade rural inédita para a época, porque, sendo ele parente dos escravos, os protegia e permitia que tanto estes quanto os parentes de sua mulher construíssem pequenas casas de pau-a-pique e vivessem na comunidade de lavoura de subsistência ao lado do trabalho que prestavam aos proprietários. Nesta comunidade os negros eram respeitados e viviam como uma família unida e cooperativa, o que fez com que muitos desses negros continuassem ali mesmo após a libertação dos escravos.

Ainda assim, ressalta-se que apesar de Santa Maria ter a mesma origem de Sacramento, não há ligação entre elas, mas sua história teve grande relevância para a construção da identidade negra neste município.

A região de Sacramento era conhecida no Século XVIII como sertão da Farinha Podre. De terras férteis que continham metais e pedras preciosas, era habitada por tribos indígenas e grupos de negros foragidos da mineração, organizados em grandes e resistentes quilombos.

Segundo o professor e sociólogo Júlio César Pereira ${ }^{1}$, a formação da comunidade negra de Sacramento, com suas manifestações culturais, veio do quilombo do Ambrósio em Araxá, localizado nas proximidades de Ibiá, dizimado a partir de 1740 . 


\section{CARNASACRA - SÍMBOLO DE RESISTÊNCIA NEGRA E OBJETO DE MANIFESTAÇÃO POPULAR}

O progresso da cidade veio com o plantio do café, com a abertura do trânsito pela ponte de Jaguara em 1861 e a criação da Companhia Mogiana de Estradas de Ferro e Navegação.

Uma cidade ruralista com uma economia baseada nas atividades agropecuárias, possui como principais atividades econômicas: latícinios, extração de minerais, indústria de madeira, indústria de bebidas, indústria de produtos alimentícios, agropecuária.

O sistema de ensino é formado na zona urbana por creches, pré-escolas, escolas de ensino fundamental e ensino médio, além de uma escola de ensino especial. $\mathrm{Na}$ zona rural, há duas escolas de ensino fundamental. Há também escolas de alfabetização de jovens e adultos e ensino à distância.

A cidade conta com diversas manifestações culturais: a Folia de Reis desde 1988, os Encontros de Ternos, Congada e Moçambique existentes a mais de 30 anos, o Encontro de Tropeiros, Romarias, Cavalgada, Capoeira, festejos à Nossa Senhora do Rosário, São Benedito, Nossa Senhora Aparecida, Nossa Senhora da Abadia e da Padroeira N. Sr ${ }^{\mathrm{a}}$ do Patrocínio do Santíssimo Sacramento.

Em 2007, criou-se na cidade o Centro de Memória e Cultura Negra, formado pelas comunidades Terno de Congada da Guarda de São Benedito, Associação Esportiva de Capoeira de Sacramento, Movimento de Integração e Conscientização da Cultura Negra e a Comunidade Identidade Negra idealizado por Túlio Costa ${ }^{2}$. O centro foi criado em parceria com a Prefeitura Municipal e gerido por uma diretoria formada com membros dos movimentos negros da cidade que surgiram na década de 80 .

\section{As manifestações carnavalescas}

Os negros que chegaram em Sacramento instalaram-se na periferia por volta de 1917, e a partir desta época, o carnaval surge como uma manifestação da cultura urbana e constituiu-se em espaço de sociabilidade e construção da identidade desta comunidade. O carnaval desenvolve-se como uma forma disfarçada de resistência.

Para Hall:

"Não importa o quão deformadas, cooptadas e inautênticas sejam as formas como os negros e as tradições e comunidades negras pareçam ou sejam representadas na cultura popular, vê-se ainda figuras e repertórios, aos quais a cultura popular recorre, as experiências que estão por trás delas. Em sua expressividade, sua musicalidade, sua oralidade e na sua rica, profunda e variada atenção à fala; em suas inflexões vernaculares e locais; em sua rica produção de contranarrativas; e, sobretudo, em seu uso metafórico do vocabulário musical, a cultura popular negra tem permitido trazer à tona, até nas modalidades mistas e contraditórias da cultura popular mainstream, 


\section{CARNASACRA - SÍMBOLO DE RESISTÊNCIA NEGRA E OBJETO DE MANIFESTAÇÃO POPULAR}

elementos de um discurso que é diferente - outras formas de vida, outras tradições de representação". (2006, p. 323)

Estas manifestações ocorriam tanto no esporte, como em festas da comunidade que começaram a ocorrer por volta de 1930.

João Pereira Guimarães e Ana Barbosa Guimarães realizavam pequenas manifestações carnavalescas com suas filhas Ruth Barbosa Guimarães e Messias da Conceição Barbosa, sobrinhas, primos e amigos. Havia dois blocos, os Filhos da Lua e as Filhas da Lua, precursores da Congada, que ensaiavam num terreirão de terra batida no quintal de sua casa. As moças vestiam roupas de linho branco, os rapazes usavam roupas de marinheiro e os músicos vestiam-se com terno e gravata.

\footnotetext{
"Começou lá no quintal... nós reunia as moças vizinhas e começava a cantar, eu era a empregada do Vigilato e dormia lá e via as gravações que vinham do Rio, do carnaval sabe... mas como eu era boa de ouvido, eu pegava aquelas músicas e passava elas, e nós fazia aquela coisa (...) como Sacramento era pequenininho, não tinha luz (...) então nós brincava e dançava com a lua... por isso ele colocou o nome de Os Filhos da Lua (...) e essas roupa, quem fez foi uma pessoa, que era a mulher do chefe da estação, dona Dina... nós comprava porque eles não dava nada, era tudo nós que fazia... tudo a gente que comprava e mandava fazer e depois saia na rua....(GUIMARÃES: Depoimento concedido à autora em 19/09/2009)
}

Ruth Barbosa Guimarães ${ }^{3}$ era a que mais trabalhava em função dos cordões, movimentava a comunidade para a realização destes e captava patrocínios financeiros ou de materiais com os lojistas locais. Em 1949, Ruth mudou-se para São Paulo e sua irmã Messias da Conceição Barbosa ${ }^{4}$ deu continuidade aos cordões.

Com a morte de Conceição em 1961, o carnaval chegou a estagnar e alguns anos depois, Azor Pereira Guimarães ${ }^{5}$, irmão de Ruth e Conceição, torna-se o rei do carnaval sacramentano trazendo uma grande mudança social e tornando-o fenômeno máximo da cultura popular.

Nas décadas de 40 a 50, os negros eram proibidos de freqüentar os demais clubes da cidade e coibidos pela polícia ao realizarem qualquer tipo de manifestação. Surgiu assim a necessidade de criação de um local onde eles pudessem jogar o futebol e recrear. Fundou-se então um clube esportivo em 1958 que no ano seguinte tornou-se o Clube 13 de Maio, um clube tanto esportivo quanto social e objeto de estudo desta pesquisa.

Nos anos 70, este clube ganha destaque no setor social com a realização de peças de teatro, bailes e brincadeiras dançantes e muitos jovens, tanto brancos quanto negros, saiam dos bailes que eram realizados no Sacramento Clube e iam para o Clube 13 de Maio. 


\section{CARNASACRA - SÍMBOLO DE RESISTÊNCIA NEGRA E OBJETO DE MANIFESTAÇÃO POPULAR}

Nesta época também, o carnaval passa a receber incentivo da prefeitura com destinação de verbas e infraestrutura para as escolas que surgiam e premiação às campeãs. Surgiram as dissidências com criação de blocos, escolas e presença do povo nas ruas. Surgem as escolas Mocidade Alegre, Clube Operários, Tradição Sacramentana, Unidos do Areão e Blocos caricatos e mascarados, como o Maria Giriza e o Vai Quem Qué.

$\mathrm{Na}$ década de 80 o carnaval profissionalizou-se ocupando lugar de destaque na programação oficial no município.

Nos anos 90 intensifica-se a promoção do carnaval com a manutenção do palanque das autoridades e construção das arquibancadas. Joaquim Rosa Pinheiro, prefeito em 1994 aumenta a subvenção das escolas neste ano. A Rádio Sacramento e o Jornal $\mathrm{O}$ Estado do Triângulo tornam o evento conhecido em toda a região. $\mathrm{E}$ em 2003 há um investimento crescente da administração pública nesta festa.

Segundo Antonio Clarete Scalon, presidente da comissão organizadora do carnaval, este está classificado como um dos melhores do Triângulo Mineiro e leva para a avenida cerca de 10 mil pessoas no período dos desfiles.

O carnaval sacramentano passou a denominar-se CarnaSacra, possui 5 escolas de samba e é realizado na Avenida Visconde do Rio Branco em um período de 4 dias.

Dessas escolas, somente a 13 de Maio e a Acadêmicos do Borá (2007) utilizam mão-de-obra de Sacramento para a confecção de suas fantasias e carros alegóricos, as demais alugam das cidades de Rio Claro e Poços de Caldas.

A Escola de Samba Beija Flor Sacramentano nasceu em 1995, composta por ex-integrantes da Mocidade Alegre Sacramentana (1976), considerada a primeira escola da cidade.

Há ainda as escolas Unidos do Areão (2001) e o Clube Operários, da qual Azor foi um dos fundadores com Odorico Vieira na década de 70.

\section{A Escola de Samba 13 de Maio e sua origem}

Para esta pesquisa, escolheu-se a Escola de Samba 13 de Maio, por se tratar de uma escola criada com o objetivo de inclusão do negro na comunidade e que foi marcada por conflitos sociais e políticos. Como sua origem está ligada ao futebol, a história se dará com a fundação do XIII de Maio Foot-Bol Club ${ }^{6}$, um clube que visava servir de instrumento social, recreativo e formação para o negro na cidade de 


\section{CARNASACRA - SÍMBOLO DE RESISTÊNCIA NEGRA E OBJETO DE MANIFESTAÇÃO POPULAR}

Sacramento e tornou-se o espaço para a manifestação do carnaval.

Benedito Roberto Ferreira, músico da banda da Associação Musical, composta apenas por músicos negros, se juntou a um grupo de amigos que já vinha discutindo a questão social do negro há algum tempo, como Azor Pereira Guimarães, "dona” Eva Maria do Nascimento, José Francisco Pereira, Matuzalém Ferreira, Dezidério Alcides do Nascimento e Alzamor Ferreira e fundaram em 1953 o Sacramento Futebol Clube.

Em 1957 este clube se extinguiu e os jogadores passaram a se reunir no terreirão das máquinas, onde esboçaram o que viria a ser o XIII de Maio Foot-Bol Club. Em 1958 iniciaram a captura de material e assinaturas na esperança de realizar uma possível diretoria e passaram da arrecadação de capital e consultoria jurídica, para a compra do terreno e fundação do clube, a inúmeros empecilhos, como a escolha do terreno, a luta para arrecadação de verba e problemas financeiros para conseguirem cumprir com as promissórias, o desenvolvimento de um estatuto e formalização deste em ata, assim como seu registro. A Ata de fundação saiu apenas em 1959, ano em que foi oficializada uma diretoria, com uma grande manifestação pública. Porém houve sedes provisórias até a construção definitiva em 1996, quando festas, reuniões e ensaios de carnaval passaram a realizar-se na sede.

A partir da década de 70 , as moças passaram a realizar concursos de rainha do carnaval e apresentações de teatro onde transmitiam o ideal e a condição social, moral e estética. Também faziam excursões por cidades vizinhas em bailes e festas, e intercâmbio com os clubes de Araxá e com o Elite Clube de Uberaba, de onde traziam moças para desfilarem suas fantasias ou serem passistas com seus pares masculinos.

O XIII de Maio Foot-Bol Club foi um clube idealizado por famílias que ainda o freqüentam e lutam por seu ideal. Nomes como a família Nascimento, a família Ferreira, a família Pereira, a família Rufino, a família Felício, a família Gomes de Menezes, foram importantes para o desenvolvimento da cultura carnavalesca da cidade.

O que começou como resistência, tornou-se uma movimentação cultural e econômica nunca antes presenciada pela comunidade negra na cidade.

No carnaval de 1971, a diretoria do 13 de Maio convida o Sacramento Clube para se apresentar com eles na avenida. A comunidade do Sacramento Clube passou, a partir desta data, a acompanhar a escola de samba com um bloco, uma espécie de "vai-quem-quer".

No final dos anos 70, o 13 de Maio entra em decadência social. A mídia toma espaço e esta manifestação torna-se fenômeno de massa. 


\section{CARNASACRA - SÍMBOLO DE RESISTÊNCIA NEGRA E OBJETO DE MANIFESTAÇÃO POPULAR}

Segundo Ruth Barbosa Guimarães, “(...) agora o carnaval é um luxo (...) antes não tinha nada disso, era só pra divertir as famílias." (Depoimento concedido em $19 / 09 / 2009$ )

Túlio Costa coloca: “O 13 de Maio foi fundado por negros que buscavam oportunidades de se divertirem em um local decente, que queriam se organizar como um grupo social forte, para que eles e seus descendentes fossem respeitados como cidadãos e não como sub-classe da sociedade sacramentana (...) acabou tudo o que havia de idealismo na visão dos fundadores (...). As pessoas que se postulam a ser dirigentes do 13 de Maio deveriam conhecer sua história (...) acabou a paixão da maioria dos integrantes das escolas de samba por suas agremiações, a pureza de desfilar apenas pelo gosto de brincar (...)". (Entrevista concecida em 10/08/2009)

Segundo Pereira, a formação do Clube 13 de Maio trazia diversas vertentes: uma permeada por motivações puramente étnicas em que ficavam claras as condições do cidadão descendente das etnias com raízes africanas, a sua condição social global de valores, ou seja, uma crença e uma cultura distintas dentro de uma sociedade que não a entendia como inerentes a um povo, mas como cultura brasileira, e outra vertente que percebia que cidadãos socialmente não integrados não se sentiam socialmente capacitados para fazerem parte, a exemplo de um baile de gala, de uma sociedade onde eram muitas as imposições sociais, atreladas aos seus segmentos sociais dominantes. (2008, p. 20)

Para Hall:

“(...) é somente pelo modo no qual representamos e imaginamos a nós mesmos que chegamos
a saber como nos constituímos e quem somos. Não há como escapar de políticas de repressão,
e não podemos lidar com a idéia de "como a vida realmente é lá fora" como uma espécie de teste
para medir o acerto ou o erro político de uma dada estratégia ou texto cultural. (..)" (2006, p.
327)

Clóvis Moura (1992) refere-se à degradação da cultura do negro enquanto grupo específico de resistência, citando a transformação ocorrida com as escolas de samba no Brasil, que: “(...) perderam a sua especificidade de protesto simbólico espontâneo de antigamente (...) subordinando-se a instituições ou grupos financiadores que as despersonalizam (...)." (Disponível no site: http:/www.folcloresenzala.com/ estudos/bantos.html. Acessado em 01/09/2009).

Ainda segundo Moura, os negros possuem a característica de recriar seu próprio universo simbólico através de suas próprias estratégias de resistência, preservando assim suas culturas originais.

Para Hall, a importância da cultura popular reside em ser um terreno de luta 


\section{CARNASACRA - SÍMBOLO DE RESISTÊNCIA NEGRA E OBJETO DE MANIFESTAÇÃO POPULAR}

pelo poder, de consentimento e resistência populares, abarcando, assim, elementos da cultura de massa, da cultura tradicional e das práticas contemporâneas de produção e consumo culturais. (2006, p. 330)

Tomando como base o sentido do carnaval como festa, pode-se citar uma colocação de Maria Nazareth Ferreira (2005), em que a festa, para a comunidade, era um momento de afirmação da identidade coletiva, através do qual o indivíduo tomava consciência de seu "pertencimento" a determinado grupo, assumindo o papel de protagonista de sua própria história. “(...) é colocar-se diante do espelho, procurando a si mesmo e à sua identidade; é buscar reencontrar as garantias histórico-culturais, reconfirmando-as na força da representação, no ato comunicativo e comunitário". (Disponível no site: http://www.cebela.org.br/imagens/Materia/1ART3Nazareth.pdf. Acessado em 21/07/2009).

Bakhtin (2007) coloca que: "o humor do povo nega, mas revive e renova ao mesmo tempo. Este é o verdadeiro motivo dos carnavais desempenharem um papel ainda mais importante durante os momentos de crise política, em especial nos regimes opressores: criticando e buscando novas abordagens". (Disponível no site: http: //sare.unianhanguera.edu.br/index.php/rencp/article/viewArticle/250. Acessado em 20/08/2009).

Ainda segundo Bakhtin (2007), na maioria dos casos, as expressões carnavalescas não são apenas uma resistência a dominação, mas também uma fuga, um refúgio no qual se pode transcender e reinventar um passado oprimido.

Gontijo (2007) diz que a cidadania só se exerce de forma plena a partir de situações ritualizadas, como festas, grandes reuniões e carnavais. A experiência individual do conjunto dessas situações é que faz do indivíduo um pleno cidadão.

\footnotetext{
"É através da arte e da (re)apropriação cultural - e, principalmente,da chamada "cultura popular" ou "tradicional", por oposição absurda à erroneamente chamada "cultura erudita" - que um povo se constitui enquanto nação e reforça o ideal da diversidade cultural e do respeito à convivência das diferenças". (Disponível no site: http://www.pi.gov.br/download/200511/CCOM04_ de1de8a7eb.pd. Acessado em 16/08/2009).
}

Carlo Ginzburg (2006), quando se utiliza do termo "cultura" coloca que esta assume seu caráter mais antropológico englobando as atitudes, o comportamento e as crenças das classes subalternas de uma determinada fase histórica. Ao unir o conceito de classes ao estudo das práticas populares, o autor expõe o conflito social e demonstra a dinâmica da circularidade cultural na relação entre a cultura dominante e a popular. 


\section{CARNASACRA - SÍMBOLO DE RESISTÊNCIA NEGRA E OBJETO DE MANIFESTAÇÃO POPULAR}

\section{Considerações finais}

Através das observações feitas pelos autores e a observação direta do carnaval sacramentano, assim como da análise de todo o material iconográfico e reportagens do período de 1926 à 2009, percebeu-se que a Escola de Samba 13 de Maio deixou de ter predominância negra em sua composição, tanto nos destaques da escola como nos temas utilizados neste período, mas a presença dos negros ainda é marcante e a memória dos tempos passados retoma um papel fundamental para a construção de sua identidade e busca constante por seus valores na sociedade. Nota-se que esta comunidade não perdeu seu referencial simbólico, mas uma manifestação que em muitas cidades já havia se tornado fenômeno de massa, passou a ter destaque na mídia e fez seus componentes crescerem os olhos e lutarem para exercer um papel de destaque perante as cidades vizinhas.

Estes cidadãos que se esforçaram para a criação de uma estrutura social onde a comunidade negra pudesse se manifestar, passaram pelo período da ditadura militar e por conflitos sociais. Os estandartes e as bandeiras dos blocos de carnaval dos anos de 1940 eram baseados em estandartes anarquistas e a própria comunidade também mostra essa questão ao dar como sugestão para o nome do clube de Clube Operário, também exemplo da influência do movimento político operário dos anos de 1920 . Mostra-se aí uma das colocações citadas no texto, de que o povo faz críticas construtivas e traz novas abordagens em períodos de crise, renovando seu papel na sociedade, recriando e reinterpretando valores que nasceriam sob a bandeira simbólica das categorias marginalizadas da cultura.

A exaltação do negro nos temas utilizados pela Escola ocorreu poucas vezes num período de 50 anos. Em 1988 a escola conta a história da libertação dos escravos com o tema "Exaltando a Raça", em 1995 presta uma homenagem à Conceição através do tema "Folclore" como sendo a mais folclórica figura do carnaval sacramentano, em 1998 a escola utilizou o tema "África do Sul, renascida de uma escultura humana" evocando a figura de Nelson Mandela, em 2002 faz nova homenagem às personalidades do carnaval sacramentano e em 2008, contam os 50 anos de história da escola com o tema "13 de Maio, um Jubileu de Ouro".

Antigamente o carnaval era uma festa familiar, as famílias iam para a avenida em busca de alegria e divertimento, onde elas mesmas preparavam as fantasias ao som das marchinhas e dos cordões. Nas últimas décadas o carnaval vem passando por transformações que deram novos valores e dimensão a esta manifestação.

Desta forma, conclui-se que há uma grande necessidade de manter viva a memória negra, mas este deixa de ser seu principal foco a partir do momento que a escola passa a ganhar papel de destaque com a escolha de temas populares, utiliza- 
ção de fantasias de luxo e a permissão de entrada de indivíduos não negros para dar tamanho e "peso" a esta perante a comissão julgadora do carnaval. Ao dar "status" ao carnaval de rua, não só a diretoria do clube deixa de se posicionar perante o seu ideal de origem, mas a própria comunidade negra passa a exercer o papel de cidadão socialmente mais participativo e estes passam, assim, a acreditar na democracia multicultural como forma de agregação dos valores pertinentes a comunidade negra e não negra, dando características de fenômeno de massa à esta manifestação.

\section{Referências bibliográficas}

COVRE, M. L. M.; MANZINI-COVRE,M.L. “O Que é Cidadania?” São Paulo: Ed. Brasiliense, 1991.

FERREIRA, Maria Nazareth. "Alternativas Metodológicas para Produção Científica. São Paulo: CELACC - ECA/USP, 2006.

"Identidade Cultural e Turismo Emancipador". São Paulo: CELACC - ECA/ USP, 2005.

GINZBURG, Carlo. "O Queijo e os Vermes: o cotidiano e as idéias de um moleiro perseguido pela Inquisição”. São Paulo: Companhia das Letras, 2006.

HALL, Stuart. "Da Diáspora: Identidade e Mediações Culturais". Belo Horizonte: UFMG, 2003.

MOURA, Clóvis. "Brasil: As raízes do protesto negro”. São Paulo: Global, 1983.

ORTIZ, Renato. "Cultura Brasileira e Identidade Nacional”. São Paulo: Cortez, 2001.

POGETTI, Carlos. "Da Pré-História a Santa Maria: identificação dos primeiros habitantes do Brasil". Franca: Sírius Editora, 2008.

PEREIRA, Julio César. "Sancas e Marimbas: A Saga do Terreirão". Sacramento: Editora PrismaGraf, 2008.

SANTOS, Milton. “O Lugar e o Cotidiano”. São Paulo: Hucitec, 1996.

SANTOS, J.L. “O que é Cultura”. São Paulo: Ed. Brasiliense, 2001.

\section{Referências periódicas}

Jornal "A Semana" (período de1925 a 1930).

Jornal "O Estado do Triângulo" (período de1968 a 2009).

Jornal de Sacramento (período de 1979 a 1982).

Revista "Destaque In", Ano 9. n 49. janeiro-fevereiro de 2003. 


\section{CARNASACRA - SÍMBOLO DE RESISTÊNCIA NEGRA E OBJETO DE MANIFESTAÇÃO POPULAR}

\section{Webgrafia}

BAKHTIN, M. (1968). "Rabelais e Seu Mundo". Cambridge: O MIT Pressione, 2007. Disponível no site: http://sare.unianhanguera.edu.br/index.php/rencp/article/ viewArticle/250. Acessado em 20/08/2009 às 22:15.

FERREIRA, Maria Nazareth. "Os Desafios da Produção Científica no Neoliberalismo: as culturas e comunicação subalternas". Disponível no site: www.cebela.org.br/ imagens/Materia/01ART05\%20Maria\%20Nazareth.pdf. Acessado em 20/07/2009 às $21: 56$.

. “As Festas Populares na Expansão do Turismo: a experiência italiana”. $2^{\mathrm{a}}$ edição, revista e ampliada. São Paulo. Arte\&Ciência, 2005. Disponível no site: http:// www.cebela.org.br/imagens/Materia/1ART3Nazareth.pdf. Acessado em 21/07/2009 às 19:32.

GONTIJO, F. "Identidade Cultural, Ritual e Cidadania: considerações preliminares acerca dos festivais de arte no Piauí", 2007. Disponível no site: http://www.pi.gov.br/ download/200511/CCOM04_de1de8a7eb.pd. Acessado em 16/08/2009 às 20:40.

HALL, Stuart. "A Identidade Cultural na Pós-Modernidade”. Trad.: Tomas Tadeu da Silva e Guacira Lopes Louro. 9ª . Edição, Rio de Janeiro: DP\&A, 2004. Disponível no site: http://www.usp.br/neinb/files/identidade_e_multiculturalismo.pdf. Acessado em 08/08/2009 às 17:33.

MOURA, Clóvis. "História do Negro Brasileiro". Editora Ática S.A., São Paulo 1992 Documentos publicados em São Paulo - Museu de Arte de São Paulo Assis Chateaubriand, 1981. Disponível no site: http://www.folcloresenzala.com/estudos/ bantos.html. Acessado em 01/09/2009 às 18:24.

Site Oficial de Sacramento. Disponível em: www.sacramento.com.br. Acessado em $30 / 01 / 2009$ às $19: 15$.

SacraHome - O Portal de Sacramento MG. Disponível em:www.sacrahome.net. Acessado em 30/01/2009 às 19:37.

Prefeitura de Sacramento. Disponível em: www.sacramento.mg.gov.br. Acessado em 30/01/2009 às 20:12.

Destaque IN - Revista Cultural de Sacramento e Região. Disponível em: http: //destaquein.sacrahome.net/node/15. Acessado em 20/03/2009 às 15:25.

SacraHome - O Estado do Triângulo. Disponível em: http://sacrahome.net/ oestadotriangulo. Acessado em 02/04/2009 às 15:43.

Sua Pesquisa.com. Disponível em: www.suapesquisa.com/carnaval. Acessado em 30/06/2009 às 18:36.

Carnaval do Brasil. Disponível em: www.carnavaldobrasil.com.br. Acessado em 30/ 06/2009 às 23:12.

Brasil, Mitos e Lendas. Disponível em: www.rosanevolpatto.trd.br. Acessado em 01/ 08/2009 às 00:20.

Sacranews - O Jornal diário de Sacramento. Disponível em: http:// www.sacranews.jor.br. Acessado em 24/08/2009 às 21:46. 
Netlog - "Fórum/Arquivo/Um texto muito rico - Movimento Negro Brasileiro". Disponível em: http://pt.netlog.com/groups/DaNieLrAfaH/forum/messageid=308942. Acessado em 23/09/2009 às 20:33.

Blog Historia do Futebol. Disponível em: http://blog.soccerlogos.com.br/2008/03/ 13/clube-atletico-sacramentano-de-sacramento-mg. Acessado em 01/08/2009 às 00: 30 .

\section{Videografia}

"Família Alcântara". Gênero: Documentário, Brasil: 2006.

“Orfeu Negro”. Gênero: Drama/romance, Brasil: 1959.

\section{Notas}

${ }^{1}$ Júlio César Pereira, professor e sociólogo, atuante no trabalho de militância negra desde 1985 em Uberaba e atualmente atua no Protea - Movimento Estadual de Consciência Negra do Estado de São Paulo.

${ }^{2}$ Túlio Marcos Anselmo da Costa - presidente da Comunidade Identidade Negra e idealizador do Centro de Memória e Cultura Negra. Em entrevista concedida em 10/08/2009 fala sobre sua participação no carnaval sacramentano e atuação como pesquisador desta manifestação.

${ }^{3}$ Ruth Barbosa Guimarães completará 100 anos em 2010 e é a memória viva do carnaval sacramentano. Em depoimento concedido a autora em 19/09/2009, contou suas lembranças do início desta manifestação em que teve papel fundamental no final dos anos de 1930.

${ }^{4}$ Messias da Conceição Barbosa foi aclamada como grande carnavalesca sacramentana com direito a troféu com seu nome.

${ }^{5}$ Azor Pereira Guimarães tornou-se o rei do carnaval. Teve passagem pelo 13 de Maio Futebol Clube e criou o Clube Operários com Odorico Vieira na década de 70. Há também um troféu dedicado à seu nome.

${ }^{6}$ Denominação dada ao clube conforme Ata de Fundação de 15 de junho de 1959. 